\title{
Are Topical Steroids a Risk Factor for Tube Exposure in Glaucoma Drainage Devices?
}

\author{
Alex M Ragan (1D' \\ Gavin Docherty $\mathbb{D}^{2}$ \\ Andrew Crichton' \\ 'Division of Ophthalmology, Department \\ of Surgery, University of Calgary, Calgary, \\ Alberta, Canada; ${ }^{2}$ Division of \\ Ophthalmology, Department of Surgery, \\ Kelowna, British Columbia, Canada
}

Correspondence: Andrew Crichton Email andrew.

crichton@albertahealthservices.ca
Glaucoma drainage devices represent an important addition to the surgical armamentarium for controlling glaucoma. Their efficacy in reducing intraocular pressure, together with a comparable complication profile when compared to trabeculectomy, has led to increasing utilization. As utilization of glaucoma drainage devices has increased, so has knowledge of their associated complications.

One of the most challenging of these complications is the exposure of the device which may lead to inflammation, hypotony, phthisis, and endophthalmitis. A small body of literature has identified possible risk factors associated with glaucoma drainage device exposure. These risk factors include an inferior versus superior placement of the implant, prior or concurrent ocular surgery, patch graft material and thickness, older age, race, and female gender.

The study by Chaku et al entitled "Risk factors for tube exposure as a late complication of glaucoma drainage implant surgery," has added to this literature. ${ }^{1}$ In their study, the authors presented the results of a retrospective case-controlled observational study of 64 eyes with glaucoma drainage device surgery for the purpose of assessing risk factors for tube exposure. Statistically significant risk factors identified in the study included younger age and pre-operative inflammation. Interestingly, the study also revealed a statistically significant association between topical steroid use and tube exposure. This association had not previously been identified and was not emphasized by the authors in their conclusions.

While topical steroids are effective at decreasing inflammation, they are also known to have adverse effects on conjunctival and corneoscleral structure and healing. Specifically, topical steroids have been implicated in conjunctival thinning, corneoscleral melting, and the inhibition of healing at both an epithelial and stromal level in ocular tissues. ${ }^{1-7}$

In the context of glaucoma filtration devices, local tissues have been surgically disrupted, blood supply may be attenuated (especially in relation to overlying patch grafts), and tissues are under mechanical and inflammatory stresses from the implant. The addition of topical steroid may represent a further exacerbating factor that contributes to the inhibition of wound healing and the thinning of tissue over the tube.

This is not to recommend the exclusion of topical steroids in their entirety within the context of filtration device management. Rather, their use must be judiciously managed depending on the clinical context, with an awareness that they may be of clinical benefit or detriment depending on the situation. Two examples, of several similar cases from our clinical practice, illustrate this point. 
Our first patient was an eight-year-old male who was originally referred for intraocular hypertension in the context of monocular uveitic glaucoma. Combined cataract and trabeculectomy was performed, followed by subsequent implantation of two glaucoma drainage devices. The first device was a Molteno Glaucoma Drainage Device (Molteno Ophthalmic Ltd., Dunedin, New Zealand) which was placed in the superotemporal quadrant. A Tube Extender (New World Medical, Inc., Rancho Cucamonga, CA) was later attached to this device in response to retraction of the tube. Nine years later, inadequate pressure control with the first device necessitated the placement of a second implant. This implant (S3 Ahmed Glaucoma Valve, New World Medical, Inc., Rancho Cucamonga, CA) was placed in the superonasal quadrant. Both drainage devices were implanted in the conventional manner with overlying scleral patch grafts and conjunctival closure. Post-operative management consisted of topical pressure lowering medication (brimonidine tartrate $0.2 \%$, twice daily) and topical prednisolone (1\%) drops tapered from four times daily to once daily to suppress residual inflammation.

Years after the implantation of the second drainage device, the tube associated with the original implant had migrated through the scleral patch graft, but not the overlying conjunctiva (Figure 1). Through this time, the steroids were continued. However, after reading the paper by Chaku et al in 2016, the steroid was withdrawn. Inflammation in the eye has remained negligible and the thickness of tissue overlying the tube filtration device has remained stable over more than 40 months of follow-up.

Our second patient was a 41-year-old man who was referred for management of glaucoma in the right eye

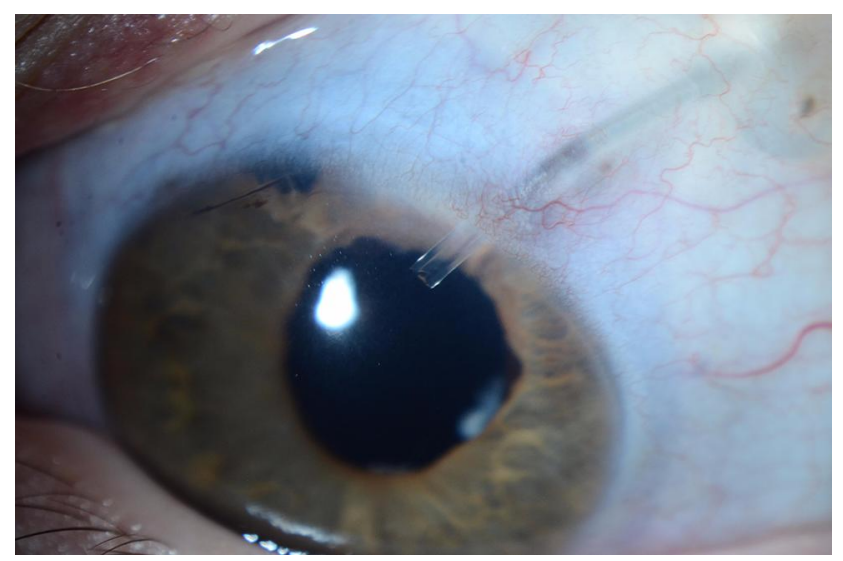

Figure I Magnified photograph of the anterior segment showing thinning of tissue overlying the glaucoma drainage device tube. following cataract surgery. Topical medical therapy was insufficient to control intraocular pressure and multiple surgical interventions were pursued. These included a superior trabeculectomy in 2004, superotemporal Ahmed Glaucoma Valve in 2007, superonasal S3 Ahmed Glaucoma Valve in 2010, iStent (Glaukos Corporation, San Clemente, California) placement in 2011, removal of the superotemporal Ahmed Valve in 2012, inferonasal placement of a Baerveldt Valve (Abbott Medical Optics, Abbot Park, Illinois) in 2013, and implantation of CyPass Micro-Stent (Alcon, Fort Worth, Texas) in 2016. Post-operative management for each of these surgeries included the use of topical steroid (difluprednate, $0.05 \%$ ), which was tapered to a single drop once daily.

In late 2016, thinning of tissue was observed in relation to the scleral patch graft overlying the tube of the superonasal Ahmed Glaucoma Valve. The topical difluprednate was discontinued and the residual tissue closely monitored for further change. Sparing use of topical steroids (prednisolone, $1 \%$; dexamethasone, $0.1 \%$ ) was subsequently employed for brief intervals after further surgeries including micropulse laser in 2017 and placement of an InnFocus Microshunt (InnFocus Inc., Miami, Florida, USA) in 2019. However, subsequent follow-up over the intervening 37 months has demonstrated no further thinning of the overlying tissue (Figure 2).

These cases are two of several in our practice with similar courses. Both patients had multiple risk factors for implant exposure including prior ocular surgeries, preexisting ocular inflammation, and anterior tube positioning. Whether the tube would have become exposed if steroids were continued is unknown, but the use of steroids was shown to be unnecessary and may have contributed to the thinning of overlying tissue.

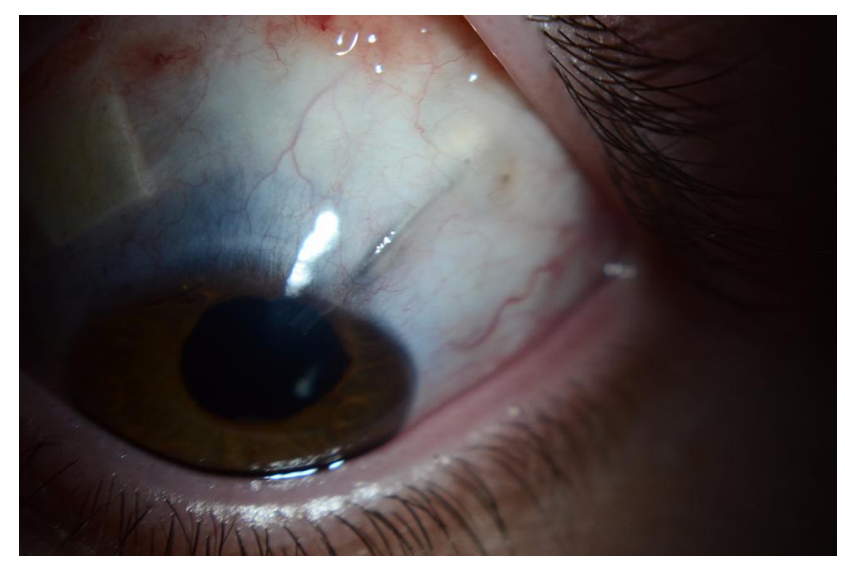

Figure 2 Magnified photograph of the anterior segment showing thinned tissue overlying the tube associated with a glaucoma drainage device. 
These cases, and others like them in our practice, highlight the importance of periodically re-evaluating the need for topical steroids; especially if there is an ocular implant at risk of exposure. Clinicians may also consider the use of lower potency steroids, non-steroidal anti-inflammatory agents, or other steroid sparing immunomodulatory therapy depending on the underlying reason for antiinflammatory treatment.

We hope that by sharing our clinical experiences that other clinicians and patients may benefit from this reassessment of the use of steroids in the context of drainage device tube exposure.

Informed patient consent was obtained for the publication of case details and images contained in this manuscript, which has been prepared in accordance with the guidelines outlined in the Declaration of Helsinki. The contents of this manuscript are exempt from review and approval of the University of Calgary Conjoint Ethics Research Board.

\section{Disclosure}

Dr Andrew Crichton reports grants and/or honoraria consulting fees from Allergan Canada Inc, Alcon Canada, Thea Pharma, Santen Inc, Aerie Pharma, and
Bausch\&Lomb, outside the submitted work. The authors report no other conflicts of interest in regard to the substance or preparation of this manuscript.

\section{References}

1. Chaku M, Netland PA, Ishida K, Rhee DJ. Risk factors for tube exposure as a late complication of glaucoma drainage implant surgery. Clin Ophthalmol. 2016;10:547-553. doi:10.2147/OPTH. S104029

2. Chang L, Crowston JG, Cordeiro MF, Akbar AN, Khaw PT. The role of the immune system in conjunctival wound healing after glaucoma surgery. Surv Ophthalmol. 2000;45(1):49-68. doi:10.1016/S00396257(00)00135-1

3. Feldman RM, ed. Complications of Glaucoma Surgery. Oxford University Press; 2013.

4. Skuta GL, Fechtner RD. Wound healing in glaucoma filtering surgery. Surv Ophthalmol. 2003;48(3):314-346. doi:10.1016/S0039-6257(03) 00038-9

5. Tuli SS, Schultz GS, Downer DM. Science and strategy for preventing and managing corneal ulceration. Ocul Surf. 2007;5(1):23-39. doi:10.1016/S1542-0124(12)70050-2

6. Aquavella JV, Gasset AR, Dohlman CH. Corticosteroids in corneal wound healing. Am J Ophthalmol. 1964;58:621-626. doi:10.1016/ 0002-9394(64)91380-7

7. Barba KR, Samy A, Lai C, et al. Effect of topical anti-inflammatory drugs on corneal and limbal wound healing. J Cataract Refract Surg. 2000;26:893-897. doi:10.1016/S0886-3350(00)00364-3
Clinical Ophthalmology

\section{Publish your work in this journal}

Clinical Ophthalmology is an international, peer-reviewed journal covering all subspecialties within ophthalmology. Key topics include: Optometry; Visual science; Pharmacology and drug therapy in eye diseases; Basic Sciences; Primary and Secondary eye care; Patient Safety and Quality of Care Improvements. This journal is indexed on PubMed

Submit your manuscript here: https://www.dovepress.com/clinical-ophthalmology-journal

\section{Dovepress}

Central and CAS, and is the official journal of The Society of Clinical Ophthalmology (SCO). The manuscript management system is completely online and includes a very quick and fair peer-review system, which is all easy to use. Visit http://www.dovepress.com/ testimonials.php to read real quotes from published authors. 